\title{
Integron Expression in Multidrug-Resistant Escherichia coli Isolated from House Flies within the Hospital ${ }^{\dagger}$
}

\author{
Atchariya YOSBOONRUANG*, Anong KIDDEE, \\ Chatsuda BOONDUANG and Phannarai PIBALPAKDEE
}

\begin{abstract}
Department of Microbiology and Parasitology, School of Medical Sciences, University of Phayao, Phayao 56000, Thailand
\end{abstract}

("Corresponding author’s e-mail: f.atchariya@hotmail.com, atchariya.yo@up.ac.th)

Received: 31 March 2018, Revised: 30 July 2018, Accepted: 26 August 2018

\begin{abstract}
Escherichia coli is a serious cause of a variety of hospital-acquired infections and commonly contributes to the environment by house flies. Integrons, particularly class 1 integrons, are the genetic elements that play an important role in the horizontal transfer of antimicrobial resistance mechanism. This mechanism is commonly found in Enterobacteriaceae, especially E. coli. In this study, we aim to investigate the occurrence and antimicrobial resistance patterns of $E$. coli isolated from the house flies in Phayao hospital and to determine the gene expression of class 1 integrons in those isolates of $E$. coli. Totally, 70 isolates of $E$. coli were isolated from 60 house flies collected from the hospital. Fiftyseven of the isolates ( $81.43 \%$ ) were multidrug resistance (MDR) and highly resistant to $\beta$-lactams, tetracyclines, and sulfonamides. Of 57 isolates of MDR-E. coli, 20 isolates $(35 \%)$ were found to carry class 1 integron genes. Fifteen patterns of antimicrobial resistance occurred in the isolates of integron-positive E. coli. Most integron-positive $E$. coli isolates were resistant to 7 antimicrobials. Two isolates of these bacteria (10\%) were able to resist 13 out of 14 tested antimicrobials. Using PCR and sequencing analysis, an investigation showed that dfrA17-aadA5, dfrA12-aadA2 gene cassette was the most prevalent cassette $(\mathrm{n}=10 ; 50 \%)$ among the integron-positive $E$. coli isolates. Our results indicated that the presences of multidrug resistance and class 1 integrons were common in $E$. coli isolated from the houseflies in hospital. Therefore, screening for integron-positive E. coli from the hospital environment might be necessary for prevention of nosocomial infections.
\end{abstract}

Keywords: Antimicrobial resistance, class 1 integron, Escherichia coli, house flies, nosocomial spread

\section{Introduction}

Antimicrobial resistance among pathogenic bacteria and commensal bacteria appears to spread rapidly in many regions and has become a serious problem worldwide [1]. The increase of antimicrobial resistances is caused by the inappropriate selection and abuse of antimicrobials for the infection therapy of humans and animals as well as for the prophylaxis and growth production of animals [2]. The prevalence of multidrug resistant (MDR) bacteria found in human and animal isolates all over the world is increasing. MDR bacteria is the bacteria that are resistant to at least one agent in 3 or more antimicrobial classes [3]; therefore, the control of MDR distribution among bacteria should be more concerned. It has been reported that the increased MDR is caused by the

\footnotetext{
${ }^{\dagger}$ Presented at the International Conference on Biomedical Sciences 2018: March $22^{\text {nd }}-23^{\text {rd }}, 2018$
} 
http://wjst.wu.ac.th

horizontal transfer mechanism of the mobile genetic elements among Gram-negative bacteria $[2,4]$. Infectious diseases caused by MDR-pathogenic Escherichia coli lead to the increased mortality and cost. Multidrug resistance in non-pathogenic $E$. coli is responsible for being the important reservoir of resistance genes. E. coli can transfer the resistance genes through the mobile genetic elements like integrons [5] among E. coli strains and other bacteria in Enterobacteriaceae. Mobile genetic elements, such as transposons and plasmids, are known to carry integrons responsible for the resistance against multiple antimicrobials. Recently, 4 classes of integrons (classes 1, 2, 3 and 4) were found to be associated with carrying the resistance gene cassettes. Class 1 integrons most frequently found in $E$. coli and are more than 100 gene cassettes associated with antimicrobial resistance [6].

House flies (Musca domestica) are commonly found in Thailand [7]. They play an important role to the dissemination of various pathogenic bacteria such as Salmonella sp., Acinetobacter sp., Escherichia coli, Pseudomonas aeruginosa, and Staphylococcus aureus, etc. [7,8] because of their ability to travel around up to $8 \mathrm{~km}$ within $24 \mathrm{~h}$ to find food and reproductive sites. Therefore, they can spread an antimicrobial resistance between animals and humans by carrying the relevant bacteria on the surface of their exoskeleton and in the alimentary canal [9]. Onwugamba et al. have revealed that there are many reported colonization of housed flies with enteropathogenic bacteria. It has been reported that house flies can transmit these bacteria due to it not only colonize but also cause disease in humans and animals [9]. Even though the information is still limited, the evidence of carriage, vector and transmission potential of antimicrobial resistance bacteria in Iran [10], Brazil [11], Czech Republic [12], and Germany [13] has been found. Conduction of the resistant pathogenic and nonpathogenic bacteria in the environment, particularly in a hospital, affects the public health. Hospital acts as an important reservoir of resistant bacteria causing nosocomial infections. Screening for integron-positive E. coli from the hospital environment might be necessary for the monitoring of nosocomial infections.

The Southeast Asia as well as Thailand has been reported on the increasing antimicrobial resistance in clinical samples [14] whereas the data of antimicrobial resistance in mechanical vectors was scarce. Thailand has been reported on the prevalence of antimicrobial resistance in many strains of Gram-positive and -negative bacteria from the clinical samples [15-17]. Accordingly, screening for resistant E. coli from house flies, the mechanical vector, is important to control and monitor the distribution of the resistant bacteria in the hospital. In addition, Thailand had a few data on antimicrobial resistance throughout country especially the resistance from transmission vectors of the resistant bacteria in hospital. Furthermore, data on antimicrobial resistance patterns and class 1 integron gene cassettes are also not enough. In this study, we aim to investigate the occurrence and antimicrobial resistance patterns of $E$. coli isolated from the house flies in Phayao hospital, and to characterize class 1 integrons in those isolates of $E$. coli.

\section{Materials and methods}

\section{Bacterial isolation}

Escherichia coli were isolated from 60 house flies. E. coli isolates were obtained from the house flies within Phayao hospital during June and August, 2015. Each fly was randomly collected and vigorously shaken in the $0.9 \%$ saline. After removing the fly, saline was cross-streaked on Eosinmethyleneblue agar (Oxoid Limited, Basingstoke, United Kingdom) and incubated at $37{ }^{\circ} \mathrm{C}$ for $18 \mathrm{~h}$. The typical colonies were picked to identify using the standard biochemical test [15]. E. coli ATCC 25922 was used as the reference-typed strain for all tests. All strains were stored at $-80{ }^{\circ} \mathrm{C}$ until further study.

\section{Antimicrobial susceptibility test}

All E. coli isolates were investigated for the susceptibility to antimicrobials by disc diffusion method on Mueller-Hinton agar (Oxoid Limited, Basingstoke, United Kingdom) according to the Clinical and Laboratory Standards Institute (CLSI) guideline [18]. The susceptibility was investigated with 14 antimicrobial agents including penicillins (ampicillin, amoxicillin/clavulanic acid, 
http://wjst.wu.ac.th

ampicillin/sulbactam), cephalosporins (cephalothin, cefotaxime), carbapenems (meropenem, imipenem), fluoroquinolones (ciprofloxacin, norfloxacin), aminoglycosides (amikacin, gentamicin), tetracyclines (tetracycline), phenicols (chloramphenical), and folate pathway inhibitor (trimethoprimsulfamethoxazole). All antimicrobial agents were purchased from Oxoid Ltd. (Oxoid Limited, Basingstoke, United Kingdom). Intermediate isolates were determined to be resistant. E. coli ATCC25922 was used as the quality control strain. The isolate resistant to at least one agent in 3 or more antimicrobial classes was defined as a multidrug resistant E. coli (MDR-E.coli) [3].

\section{Detection of class 1 integrons by PCR}

Screening for integron was performed by directed colony PCR technique. The specific primers for integrase 1 gene (intI) were presented in Table 1. The amplification condition was performed by a cycle of pre-denaturation at $94{ }^{\circ} \mathrm{C}$ for $5 \mathrm{~min}$, and 30 cycles of $94{ }^{\circ} \mathrm{C}$ for $30 \mathrm{~s}$ (denaturing), $48{ }^{\circ} \mathrm{C}$ for 30 $\mathrm{s}$ (annealing), and $72{ }^{\circ} \mathrm{C}$ for $1 \mathrm{~min}$ (extension). The final extension was $72{ }^{\circ} \mathrm{C}$ for $7 \mathrm{~min}$. The PCR products were determined by agarose gel electrophoresis. Amplicon size was determined by comparing with the DNA marker.

\section{Characterization of variable region of class 1 integron}

All int1-positive isolates were investigated for the presence of integrons using primers 3 'CS and $5^{\prime} \mathrm{CS}$ for gene cassettes of class 1 integrons (Table 1). The PCR reaction was carried out by a cycle of pre-denaturation at $94{ }^{\circ} \mathrm{C}$ for $5 \mathrm{~min}$, and 30 cycles of denaturing at $94{ }^{\circ} \mathrm{C}$ for $45 \mathrm{~s}$, annealing at $48{ }^{\circ} \mathrm{C}$ for $45 \mathrm{~s}$, and extension at $72{ }^{\circ} \mathrm{C}$ for $5 \mathrm{~min}$. The final extension was $72{ }^{\circ} \mathrm{C}$ for $7 \mathrm{~min}$. PCR products were determined by agarose gel electrophoresis.

Table 1 Primers used for PCR amplification to detect class 1 integrons.

\begin{tabular}{llccc}
\hline Primer & Sequence $\left(\mathbf{5}^{\prime} \rightarrow \mathbf{3}^{\prime}\right)$ & Size of amplicon (bp) & Target genes & References \\
\hline Int 1-F & GCATCCTCGGTTTTCTGG & 457 & Integrase1 & {$[19]$} \\
Int 1-R & GGTGTGGCGGGCTTCGTG & & & \\
In5'CS & GGCATCCAAGCAGCAAG & Variable & Class 1 & {$[20]$} \\
In3'CS & AAGCAGACTTGACCTGA & & integron & \\
\hline
\end{tabular}

DNA sequencing and analysis of sequence data

Selected PCR products were purified by DNA extraction kit (Invitrogen) and analyzed by DNA sequencing. Purified DNA were sent to the commercial facility for sequencing (Krimogen). Sequences were BLAST and analyzed by the online BLAST of the National Center for Biotechnology Information (NCBI) website software.

\section{Statistical analysis}

Association between the resistance to antimicrobials and the integron expression was determined by Chi-square or Fisher's exact test (when $\mathrm{n} \leq 20$ or number in cell $<5$ ) with $p<0.05$. Analyses were performed using SPSS software for Window version 22.0.

\section{Results and discussion}

Identification of antimicrobial resistant $E$. coli isolates

Totally, 70 isolates of $E$. coli were isolated from 60 house flies collected from the hospital. All $70 \mathrm{E}$. coli isolates were tested for the susceptibility to 14 antimicrobials. The result showed that 68 isolates $(97.1 \%)$ were resistant to at least one antimicrobial while 57 isolates $(81.43 \%)$ were 
http://wjst.wu.ac.th

classified as MDR-E. coli isolates. The results indicated the high prevalence of antimicrobial resistance among $E$. coli isolates from the house flies in hospital. The multidrug resistant isolates were selected for integron detection. The percentages of the resistance to 14 antimicrobial agents for 57 isolates are shown in Table 2. Most isolates were resistant to cephalothin $(94.7 \%$ ) and ampicillin $(93.0 \%)$, which indicated high resistant frequencies. High resistant frequency to ampicillin in our study was much higher than those of the resistance in E. coli from the healthy volunteer $(35.0 \%)$ and outpatient $(65.0 \%)$ stool from hospital in Thailand [21]. A low resistant rate was observed to meropenem, imipenem, and norfloxacin (lower than $15.0 \%$ ) and no one found $100 \%$ susceptible.

The numbers of antimicrobial in co-resistance of MDR-E. coli strains are shown in Figure 1. Two isolates of the integron-positive isolates $(10.0 \%)$ and one of the integron-negative isolates $(2.7$ $\%)$ were able to resist 13 out of 14 tested antimicrobials. Most integron-positive isolates (35\%) were resistant to 7 antimicrobials while most isolates of the integron-negative isolates $(27 \%)$ were resistant to 3 out of 14 tested antimicrobials. Interestingly, the integron-positive isolates significantly exhibited high resistance to only trimethoprim/sulfamethoxazole while the resistance to other antimicrobials was not significantly different from the integron-negative isolates.

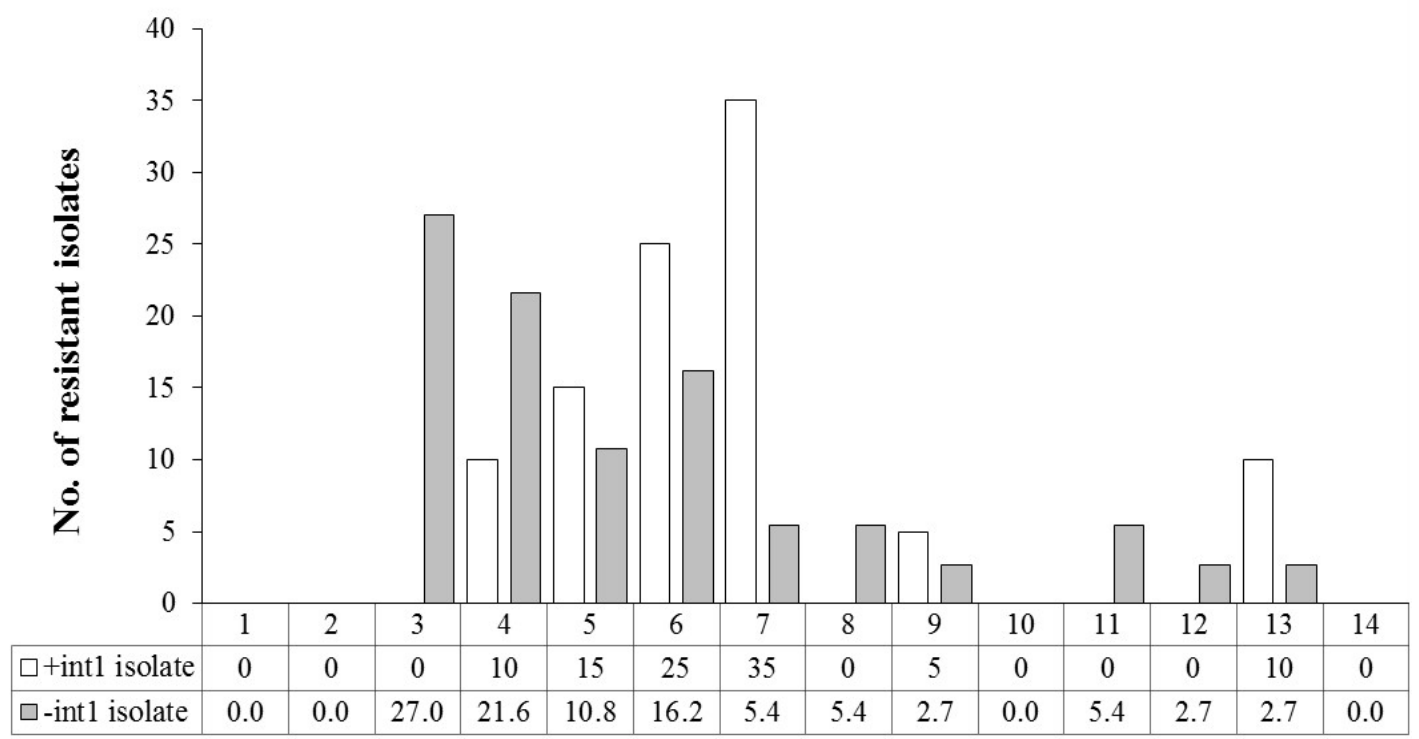

\section{No. of antimicrobials in co-resistance}

Figure 1 Frequency of multidrug resistance to 14 antimicrobial agents in the integron-positive (+int1) isolates and the integron-negative (-int1) isolates of Escherichia coli. 
http://wjst.wu.ac.th

Table 2 Antimicrobial resistance and integrons association of Escherichia coli isolates.

\begin{tabular}{|c|c|c|c|c|}
\hline \multirow[b]{2}{*}{ Antimicrobial agents } & \multicolumn{3}{|c|}{ No. $(\%)$ of resistant isolates ${ }^{\mathrm{a}}$} & \multirow[b]{2}{*}{$* p$} \\
\hline & $\begin{array}{c}\text { Total isolates } \\
(\mathrm{n}=\mathbf{5 7})\end{array}$ & $\begin{array}{c}\text { Integron-positive } \\
\text { isolates }(n=20)\end{array}$ & $\begin{array}{c}\text { Integron-negative } \\
\text { isolates }(\mathbf{n}=\mathbf{3 7})\end{array}$ & \\
\hline \multicolumn{5}{|l|}{ Penicillins } \\
\hline Ampicillin & $53(93.0)$ & $20(100)$ & $33(89.2)$ & 0.29 \\
\hline Ampicillin/sulbactam & $32(56.1)$ & $11(55.0)$ & $21(56.8)$ & 0.90 \\
\hline Amoxicillin/clavulanic acid & $11(19.3)$ & $3(15.0)$ & $8(21.6)$ & 0.73 \\
\hline \multicolumn{5}{|l|}{ Cephalosporins } \\
\hline Cephalothin & $54(94.7)$ & $19(95.0)$ & 35 (94.6) & 1.00 \\
\hline Cefotaxime & $33(57.9)$ & $12(60.0)$ & $21(56.8)$ & 0.81 \\
\hline \multicolumn{5}{|l|}{ Carbapenems } \\
\hline Meropenem & $5(8.8)$ & $2(10.0)$ & $3(8.1)$ & 1.00 \\
\hline Imipenem & $6(10.5)$ & $2(10.0)$ & $4(10.8)$ & 1.00 \\
\hline \multicolumn{5}{|l|}{ Fluoroquinolones } \\
\hline Norfloxacin & $8(14.0)$ & $2(10.0)$ & $6(16.2)$ & 0.70 \\
\hline Ciprofloxacin & $12(21.1)$ & $4(20.0)$ & $8(21.6)$ & 1.00 \\
\hline \multicolumn{5}{|l|}{ Aminoglycosides } \\
\hline Amikacin & $12(21.1)$ & $5(25.0)$ & $7(18.9)$ & 0.74 \\
\hline Gentamicin & $20(35.1)$ & $10(50.0)$ & $10(27.0)$ & 0.08 \\
\hline \multicolumn{5}{|l|}{ Tetracyclines } \\
\hline Tetracycline & $44(77.2)$ & $17(85.0)$ & $27(73.0)$ & 0.35 \\
\hline \multicolumn{5}{|l|}{ Phenicols } \\
\hline Chloramphenicol & $22(38.6)$ & $11(55.0)$ & $11(29.7)$ & 0.06 \\
\hline \multicolumn{5}{|l|}{ Folate pathway inhibitor } \\
\hline Trimethoprim-sulfamethoxazole & $26(45.6)$ & $17(85)$ & $9(24.3)$ & $<0.01$ \\
\hline
\end{tabular}

${ }^{a}$ Tested by disc diffusion method. Intermediate isolates were determined as resistant strains.

Table 3 Multidrug resistant profiles of the integron-positive Escherichia coli isolates.

\begin{tabular}{clc}
\hline Pattern type & Antimicrobial resistance & $\begin{array}{c}\text { No. (\%) of resistant strains } \\
(\mathbf{n}=\mathbf{2 0})\end{array}$ \\
\hline 1 & AMP, SAM, KF, STX & $1(5.0)$ \\
2 & AMP, AKF, CTX, SXT & $1(5.0)$ \\
3 & AMP, SAM, KF, CTX, SXT & $1(5.0)$ \\
4 & AMP, SAM, KF, CN, TE & $1(5.0)$ \\
5 & AMP, SAM, KF, SXT, TE & $1(5.0)$ \\
6 & AMP, SAM, KF, SXT, AK, TE & $1(5.0)$ \\
7 & AMP, SAM, KF, C, SXT, TE & $1(5.0)$ \\
8 & AMP, KF, CTX, C, SXT, TE & $1(5.0)$ \\
9 & AMP, KF, C, SXT, CIP, TE & $1(5.0)$ \\
10 & AMP, KF, CTX, C, AK, TE & $1(5.0)$ \\
11 & AMP, SAM, AMC, C, CIP, TE & $1(5.0)$ \\
12 & AMP, KF, CTX, C, SXT, CN, TE & $5(25.0)$ \\
13 & AMP, SAM, KF, SXT, AK, CN, TE & $1(5.0)$ \\
14 & AMP, SAM, KF, CTX, C, SXT, CN, CIP, TE & $1(5.0)$ \\
15 & AMP, AMC, SAM, KF, CTX, SXT, MEM, IPM, AK, CN, CIP, NOR, TE & $2(10.0)$ \\
\hline
\end{tabular}


http://wjst.wu.ac.th

Comparing with previous studies, the expression of class 1 integron in E. coli from the environment of Asia, including house flies (35\%; result from this study), Dongjiang river of China $(82.3 \%)$ [22] and aquaculture water in Iran (40.0\%) [23], was higher than that in Europe, such as wastewater in Poland (11.0\%) [24]. Considering the resistance-integron association, the rate of resistance to each tested antimicrobial was not different except trimethoprim-sulfamethoxazole $(85.0$ $\%$ for integron-positive and $24.3 \%$ for integron-negative isolates).

The resistance pattern of each strain was also investigated. The resistance patterns of integronpositive isolates and the major resistance patterns of the integron-negative isolates were shown in Tables 2 and 3, respectively. The integron-positive isolates displayed 15 different patterns and only 2 patterns were shared by more than 2 isolates. While, the integron-negative isolates showed 28 different patterns and 6 patterns were shared by more than 2 isolates (Table 2). The resistance pattern AMP-KF-CTX-C-SXT-CN-TE was the most frequent pattern for the integron-positive isolates while pattern AMP-KF-TE was the most frequent pattern for the integron-negative isolates (Tables 3 and 4). Comparing with the previous report on clinical $E$. coli isolates, the number of the resistant patterns of the integron-positive isolates in this study (15 patterns) was less than that of the resistant patterns of the clinical E. coli isolates in other studies (43 patterns) [21].

Table 4 Multidrug resistant profiles of the integron-negative Escherichia coli isolates.

\begin{tabular}{clc}
\hline Pattern type & Antimicrobial resistance & $\begin{array}{c}\text { No. }(\%) \text { of resistant strains } \\
(\mathbf{n}=\mathbf{3 7})\end{array}$ \\
\hline 1 & AMP, KF, TE & $4(10.8)$ \\
2 & AMP, SAM, KF & $2(5.4)$ \\
3 & AMP, KF, CTX, AK & $2(5.4)$ \\
4 & AMP, KF, CTX, C, CN, TE & $2(5.4)$ \\
5 & AMP, SAM, KF, CTX, C, TE & $3(8.1)$ \\
6 & AMP, AMC, SAM, KF, CTX, C, SXT, CN, CIP, NOR, TE & $2(5.4)$ \\
\hline
\end{tabular}

\section{Integron and gene cassette characterization}

All MDR-E.coli isolates were investigated for integrase genes and class 1 conserved region by PCR technique. Of the 57 isolates, $21(36.8 \%)$ were positive for a class 1 integrase gene by amplifying the int 1 . The $21 \mathrm{E}$. coli isolates that carried int 1 were further analyzed for class 1 integrons using $5^{\prime} \mathrm{CS}$ and $3^{\prime} \mathrm{CS}$ and the result showed that $20(35 \%)$ contained class 1 integron. The different integron patterns were shown in Table 5. Resistance gene cassettes carried on class 1 integron exhibited with the sizes ranging from $0.8 \mathrm{~kb}$ to $2.4 \mathrm{~kb}$. Among 20 integron-positive isolates, there were 6 isolates containing one amplicon and 14 isolates containing 2 amplicons with different sizes. The co-existence of 2 different integrons was confirmed that these integrons carried different gene cassettes using sequence analysis. Table 5 illustrated 7 different gene cassettes, including gene encoding resistance to trimethoprim (dfrA7, dfrA12, drfA17, dhfr 12), and aminoglycosides (aadA2, aadA5). The most common type of cassette $(d f r A)$ conferred resistance to trimethoprim, which represented $100 \%$ among all cassettes. The frequently found trimethoprim-resistant $(d f r A)$ gene cassette in the E. coli strains corresponded to the previous reports [2,25]. The array $d$ frA17-aadA5, $d$ frA12-aadA2 encoding resistance to trimethoprim and aminoglycosides was frequently found in class 1 integrons containing $E$. coli isolates in this study. The prevalence of $d f r A$ linked with aadA array in $E$. coli agreed with those reported earlier in other countries [2,25]. In Thailand, there was no report on these arrays in the integron containing $E$. coli isolates. 
http://wjst.wu.ac.th

Table 5 Gene cassette arrays of class 1 integrons of Escherichia coli isolates.

\begin{tabular}{cllc}
\hline $\begin{array}{c}\text { Integron } \\
\text { group }\end{array}$ & $\begin{array}{c}\text { Approximate size } \\
\text { of amplicon (kb) }\end{array}$ & Gene cassettes & $\begin{array}{c}\text { No. of strains carrying } \\
\text { gene cassettes }\end{array}$ \\
\hline 1 & 0.8 & $d f r A 7$ & 2 \\
2 & 1.6 & $d f r A 17$-aadA5 & 3 \\
3 & 2.2 & $d f r A 12$-aadA2 & 1 \\
4 & $0.8,2.2$ & dfrA7,dhfr12-aadA2 & 1 \\
5 & $1.5,2.1$ & dfrA12,dfrA12-aadA2 & 2 \\
6 & $1.6,2.1$ & dfrA17-aadA5,dfrA12-aadA2 & 10 \\
7 & $1.6,2.4$ & dfrA17-aadA5,dfrA12-orfF-aadA2 & 1 \\
\hline
\end{tabular}

${ }^{a}$ Resistant genes: $d f r A 7, d f r A 12, d r f A 17$ and $d h f r 12$, encoding dihydrofalate reductase; aadA2 and aadA5, encoding aminoglycoside adenyltransferase; $o r f F$, unknown open reading frame.

House flies carrying integron-positive $E$. coli are the important reservoir of integron containing isolates that can be distributed to other bacteria in environment and also in humans. The importance of integron expression implies that using one antimicrobial could contribute to the expression and transfer of a whole gene cassette. Bacteria receiving that gene might become multidrug resistance although they were exposed to only one antimicrobial agent [26].

\section{Conclusions}

The resistance to multiple antimicrobial agents of $E$. coli from house flies in the Northern Thailand hospital was commonly found $(81.43 \%)$. House flies may harbor MDR-E. coli for long time, and transfer in the environment causing the reservoir and infection risk to patients. The expression of class 1 integrons in this study revealed the potential for house flies to contribute to the environmental existence and probable distribution of MDR-E. coli in hospital. Our data could be the useful information for monitoring the antimicrobial resistance in environment through the insect vector.

\section{Acknowledgements}

This study was supported by a grant from University of Phayao (Grant No.RD59053) and School of Medical Sciences (Grant No.601008). We also thank School of Medical Sciences, University of Phayao for supporting the research facility.

\section{References}

[1] Centers for Disease Control and Prevention. National strategy for combating antibiotic-resistant bacteria. Antibiotic Resistance Treats in the United States. 2013.

[2] SH Hsu, TH Chiu, JC Pang, CH Hsuan-Yuan, GN Chang and HY Tsen. Characterisation of antimicrobial resistance patterns and class 1 integrons among Esherichia coli and Salmonella enterica serotype Cholesteraesuis strains isolated from humans and swine in Taiwan. Int. J. Antimicrob. Agents 2006; 27, 383-91.

[3] AP Magiorakos, A Srinivasan, RB Carey, Y Carmeli, ME Falagas, CG Giske, S Harbarth, JF Hindler, G Kahlmeter, B Olsson-Liljequist, DL Paterson, LB Rice, J Stelling, MJ Struelens, A Vatopoulos, JT Weber and DL Monnet. Mutidrug-resistant, extensively drug-resistant and pandrug-resistant bacteria: an international expert proposal for interim standard definitions for acquired resistance. Clin. Microbiol. Infect. 2012; 18, 268-81.

[4] MN Swartz. Human diseases caused by foodborne pathogens of animal origin. Clin. Infect. Dis. 2002; 34, S111-S122. 
http://wjst.wu.ac.th

[5] S Cocchi, E Grasselli, M Gutacker, C Benagli, M Convert and JC Piffaretti. Distribution and characterization of integrons in Escherichia coli strains of animal and human origin. FEMS Immunol. Med. Microbiol. 2007; 50, 126-32.

[6] AC Fluit and FJ Schmitz. Resistance integrons and super-integrons. Clini. Microbiol. Infect. 2004; 10, 272-88.

[7] P Suntaravitun. Flies: The important role in medicine. Songklanagarind Med. J. 2012; 30, $167-$ 78.

[8] JF Butler, AG Maruniak, F Meek and JE Maruniak. Wild Florida house flies (Musca domestica) as carriers of pathogenic bacteria. Fla. Entomol. 2010; 93, 218-23.

[9] FC Onwugamba, JR Fitzgerald, K Rochon, L Guardabassi, A Alabi, S Kühneg, MP Grobusch and F Schaumburg. The role of 'filth flies' in the spread of antimicrobial resistance. Travel. Med. Infect. Dis. 2018; 22, 8-17.

[10] R Ranjbar, M Izadi, TT Hafshejani and F Khamesipour. Molecular detection and antimicrobial resistance of Klebsiella pneumoniae from house flies (Musca domestica) in kitchens, farms, hospitals and slaughterhouses. J. Infect. Public Health 2016; 9, 499-505.

[11] TDS Alves, GHB Lara, RP Maluta, MG Ribeiro and DDS Leite. Carrier flies of multidrugresistant Escherichia coli as potential dissemination agent in dairy farm environment. Sci. Total Environ. 2018; 633, 1345-51.

[12] J Rybaríková, M Dolejská, D Materna, I Literák and A Cízek. Phenotypic and genotypic characteristics of antimicrobial resistant Escherichia coli isolated from symbovine flies, cattle and sympatric insectivorous house martins from a farm in the Czech Republic (2006-2007). Res. Vet. Sci. 2010; 89, 179-89.

[13] F Schaumburg, FC Onwugamba, R Akulenko, G Peters, A Mellmann, R Köck and K Becker. A geospatial analysis of flies and the spread of antimicrobial resistant bacteria. Int. J. Med. Microbiol. 2016; 306, 566-71.

[14] ES Lestari, JA Severin and H Verbrugh. Antibacterial resistance among pathogenic bacteria in Southeast Asia. Southeast Asian J. Trop. Med. 2012; 43, 385-422.

[15] S Pitikultang, $\mathrm{CH}$ Munsawaengsub and $\mathrm{CH}$ Chanyasanha. Factors associated with pharyngeal carriage of Streptococcus pneumoniae and Antimicrobial resistance in healthy children attending day-care center of a health promotional hospital. J. Public Health 2010; 40, 123-35.

[16] P Pattarach, S Pitikultang, CH Chanyasanha and D Sujirarat. Staphylococcus aureus and methicillin-resistant Staphylococcus aureus among outpatients with skin and soft tissue infections at Prachuaphhirikhan general, Hua Hin and Pranburi hospital. J. Public Health 2011; 40, 173-82.

[17] A Yosboonruang, C Jitsatthra and L Tharawet. Incidence of resistant bacteria isolated from medical devices in intensive care unit of the hospital. J. Public Health 2016; 47, 222-4.

[18] Clinical and Laboratory Standards Institute. Performance Standards for Antimicrobial Susceptibility Testing; Twenty-fourth Informational Supplement. Document M100-S24. Wayne, PA, 2014.

[19] N Shibata, Y Doi, K Yamane, T Yagi, H Kurokawa, K Shibayama, H Kato, K Kai and Y Arakawa. PCR typing of genetic determinants for metallo-beta-lactamases and integrases carried by gram-negative bacteria isolated in Japan, with focus on the class 3 integron. J. Clin. Microbiol. 2003; 41, 5407-13.

[20] C Lévesque, L Piché, C Larose and PH Roy. PCR mapping of integrons reveals several novel combinations of resistance genes. Antimicrob. Agents Chemother. 1995; 39, 185-91.

[21] S Phongpaichit, K Wuttananupan and W Samasanti. Class 1 integrons and multidrug resistance among Escherichia coli isolates from human stools. Southeast Asian J. Trop. Med. 2008; 39, 279-87.

[22] HC Su, GG Ying, R Tao, RQ Zhang, JL Zhao and YS Liu. Class 1 integrons, sul resistance genes and antibiotic resistance in Escherichia coli isolated from Dongjiang River, South. China Environ. Pollut. 2012; 169, 42-9. 
http://wjst.wu.ac.th

[23] E Tajbakhash, F Khamesipour, R Ranjbar and IF Ugwu. Prevalence of class 1 and 2 integrons in multi-drug resistant Escherichia coli isolated from aquaculture water in Chaharmahal Va Bakhtiari province, Iran. Ann. Clin. Microbiol. Antimicrob. 2015; 14, 1-5.

[24] R Koczura, J Mokracka, L Jabłońska, E Gozdecka, M Kubek and A Kaznowski. Antimicrobial resistance of integron-harboring Escherichia coli isolates from clinical samples, wastewater treatment plant and river water. Sci. Total Environ. 2012; 414, 680-5.

[25] LL Chang, TM Chang and CY Chang. Variable gene cassette patterns of class 1 integronassociated drug-resistant Escherichia coli in Taiwan. Kaohsiung J. Med. Sci. 2007; 23, 273-80.

[26] SR Norrby. Integrons: Adding another threat to the use of antibiotic therapy. Clin. Infect. Dis. $2005 ; 41,10-1$. 